\title{
RAÍZES DE ÉBANO: EDUCAÇÃO COMO CAMINHO DA LIBERDADE NO CINEMA
}

Alexandra Lima da Silva ${ }^{1}$

\section{Resumo}

Este trabalho procura analisar os significados da educação a partir de um conjunto de filmes protagonizados por personagens afrodescendentes, nos Estados Unidos e no Brasil. $\mathrm{O}$ texto defende que a palavra escrita tem muita força, agindo como instrumento de transformação na experiência de homens e mulheres em situações de opressão. No que se refere aos aportes teóricos, o artigo dialoga com as contribuições de Davis (2016; 2017; 2018), Hooks (2017; 1995), Ferro (1992), dentre outros. E conclui que a educação e os usos da palavra escrita são caminhos para a emancipação. Assim, em tempos de relações fluídas, permeadas pela virtualidade e pela égide das redes sociais e da superficialidade, a História da Educação tem importante papel ao promover a reflexão crítica, além de combater preconceitos e estereótipos na luta por um mundo mais justo e igualitário. Nesse contexto de resistência, o cinema é um aliado e fonte de conhecimento.

Palavras-chave: Afrodescedentes. Leitura. Escrita. Cinema. Educação.

\section{ELBONY ROOTS: EDUCATION AS A PATH OF FREEDOM IN THE MOVIE THEATER}

\begin{abstract}
This work tries to analyze the meanings of the education from a set of films carried out by characters afro-descendants, in the United States and Brazil. The text argues that the written word has great force, acting as an instrument of transformation in the experience of men and women in situations of oppression. In terms of theoretical contributions, the article talks about the contributions of Davis (2016, 2017, 2018), Hooks (2017, 1995), Ferro (1992), among others. And he concludes that education and the use of the written word are ways of emancipation. Thus, in times of fluid relations, permeated by the virtuality and aegis of social networks and superficiality, History of Education plays an important role in promoting critical reflection, as well as combating prejudices and stereotypes in the struggle for a more just and egalitarian world. In this context of resistance, cinema is an ally and source of knowledge.
\end{abstract}

Keywords: Afrodescendants. Reading. Writing. Movie theater. Education. 


\section{RAÍCES DE ÉBANO: EDUCACIÓN COMO CAMINO DE LA LIBERTAD EN EL CINE}

\section{Resumen}

Este trabajo busca analizar los significados de la educación a partir de un conjunto de películas hechas con personajes afrodescendientes, en los Estados Unidos y en Brasil. El texto defiende que la palabra escrita tiene mucha fuerza, actuando como instrumento de transformación en la experiencia de hombres y mujeres en situaciones de opresión. En lo que se refiere a los aportes teóricos, el artículo dialoga con las contribuciones de Davis (2016, 2017, 2018), Hooks (2017, 1995), Ferro (1992), entre otros. Concluye que la educación y los usos de la palabra escrita son caminos para la emancipación. Así, en tiempos de relaciones fluidas, permeadas por la virtualidad y por la égida de las redes sociales y de la superficialidad, la Historia de la Educación tiene un importante papel al promover la reflexión crítica, además de combatir prejuicios y estereotipos en la lucha por un mundo más justo e igualitario. En ese contexto de resistencia, el cine es un aliado y fuente de conocimiento.

Palabras clave: Afrodescendientes. Lectura. Escritura. Cine. Educación.

\section{INTRODUÇÃO}

A proposta deste trabalho é indicar a importância da educação e dos usos da palavra escrita e da leitura na experiência de homens e mulheres em situações de opressão. $O$ recorte escolhido contemplou filmes protagonizados por afrodescendentes na luta pela liberdade e igualdade, em produções nos Estados Unidos e no Brasil. O texto busca sensibilizar para as demandas colocadas pela lei 10.639 (JESUS, 2013), indicando a importância do engajamento na temática no âmbito da História da Educação, na luta por uma educação antirracista, conforme sinalizado por Felipe (2009), em estudo a partir do cinema como instrumento pedagógico para o ensino de História e Cultura Afro-brasileira e africana.

Em termos metodológicos, foram escolhidos os filmes protagonizados por atores e atrizes negros/as, em que as personagens transformaram uma realidade adversa e desfavorável a partir da educação. Na análise dos filmes, considerei o lugar de produção, o momento em que o filme foi produzido, quem dirigiu, mesmo que a preocupação maior no presente trabalho seja analisar as representações sobre a educação na experiência de afrodescendentes, nos Estados Unidos e no Brasil, desde o século XIX. Representação e representatividade importam.

A relação entre cinema e História não é novidade nos estudos históricos. Ao explorar os filmes, procuro seguir os conselhos de Marc Ferro, principalmente sobre a ideia de que "[...] o cinema pode tornar-se ainda mais ativo como agente de uma tomada de 
consciência social, com a condição de que a sociedade não seja somente um objeto de análise a mais." (FERRO, 1992, p. 15). Por essa razão, o cinema deve ser pensado de forma complexa, como objeto e fonte de análise para o historiador. Assim, neste trabalho, sigo o entendimento proposto por Ferro, no sentido de que o cinema não dá conta de toda a História, mas auxilia na compreensão das questões de nosso tempo e pode ser pensado como instrumento pedagógico no ensino de História da Educação, visando a conscientização social sobre a força da palavra escrita para os diferentes sujeitos históricos. No âmbito das publicações a respeito dos usos do cinema no ensino de História da Educação, destaco a coletânea Cinema e Ensino de História da Educação, organizada por Ribeiro, Carvalho e Souza (2013), com o objetivo de promover a formação discente a partir de linguagens diversificadas e imagéticas.

Do ponto de vista teórico, a educação como resistência e como caminho para a emancipação ancora-se na História Social, no sentido de pensar o fazer-se dos sujeitos, a partir das margens, sendo a educação e o acesso à palavra escrita compreendidos como ferramentas de luta dos sujeitos, uma vez que não se deve ignorar a dimensão relacional das construções sociais, porque que " $[$...] a história das pessoas comuns - mesmo quando estão envolvidos aspectos explicitamente políticos de sua experiência passada - não pode ser dissociada das considerações mais amplas da estrutura social", no que auxilia a se pensar concepções mais amplas da História, e não uma escrita fragmentada. (SHARPE, 1992, p. 54). Logo, todas as pessoas - homens e mulheres, ricos, pobres, negros, indígenas, brancos, governantes e governados, patrões, empregados, escravizados - passaram a ser concebidos como sujeitos da História.

Os usos das perspectivas teóricas da História Social, por exemplo, podem ser indicados como componente que explica a multiplicidade de sujeitos no fazer História da Educação, num compromisso de dar visibilidade a outros sujeitos de "fora" dos grandes temas consagrados pela historiografia; numa preocupação com a compreensão dos nexos e das relações sociais existentes. Em termos metodológicos, buscou-se aqui o cruzamento entre empiria e teoria, fundamentando os indícios obtidos nas fontes com as contribuições teóricas da História Social, no sentido de não homogeneizar as experiências, pois:

[...] homens e mulheres também retornam como sujeitos [...] não como sujeitos autônomos, "indivíduos livres", mas como pessoas que experimentam suas situações e relações produtivas determinadas como necessidades e interesses e como antagonismos, e em seguida, 'tratam' essa experiência em sua consciência e sua cultura [...]. (THOMPSON, 1981, p. 50).

As perguntas direcionadas às fontes seguem o movimento de vislumbrar as possibilidades no fazer das pessoas, para afirmar "[...] isto pôde (e pode) ser feito" (SARLO, 1997, p. 42), sobretudo na localização de documentos que permitiram identificar outros sujeitos, questionando esquecimentos, silêncios, evidenciando diferentes memórias. Situo o presente projeto no campo da História da Educação e procuro interrogar o cinema a 
partir das contribuições do historiador italiano Carlo Ginzburg, no sentido de pensar o possível de análise, "[...] unindo, ponderadamente, erudição e imaginação, provas e possibilidades." (GINZBURG, 2007, p. 311).

\title{
PALAVRAS QUE LIBERTAM: REPRESENTAÇÕES SOBRE ESCRAVIZADOS LETRADOS
}

Baseado em uma história real, O Nascimento de uma Nação (The Birth of a Nation, 2016), dirigido e protagonizado por Nate Parker, conta com atores afrodescendentes interpretando a maior parte dos personagens do filme. Centra a narrativa no ponto de vista dos próprios escravizados, e não na perspectiva de personagens brancos, como em outros filmes sobre a temática, nos Estados Unidos. O título é uma provocação ao polêmico filme mudo O nascimento de uma nação, lançado em 1915, e que foi considerado uma apologia ao racismo na época, por fazer uso de black face e por representar a Ku Klux Klan de forma heroica. Para Angela Davis, o cinema ajudou a difundir o racismo em filmes como O Nascimento de uma Nação, pois, “[...] com a ascensão da indústria cinematográfica nas primeiras décadas do século XX, os estereótipos racistas começaram a adquirir formas definitivas de percepção, processo que D. W. Griffth realizou com maestria em The Birth of a Nation." (DAVIS, 2017, p. 188).

Já a primeira cena de O nascimento de uma nação de Nate Parker (2016) exibe o menino escravizado Nat Turner (1800-1831) manuseando um livro que pertenceria ao filho de seu senhor. O jovem cativo, mostrando que era capaz de soletrar palavras, despertou o interesse de sua senhora em alfabetizá-lo, a partir de trechos da Bíblia.

Nat Turner torna-se um escravo letrado. Na vida adulta, torna-se pastor e, em 1831, liderou uma rebelião escrava no sul dos Estados Unidos (STYRON, 1968). Tal revolta motivou a criação de inúmeras leis proibindo a instrução dos escravizados nos Estados Unidos. Para Angela Davis, sujeitos como Nat Turner possuíam uma sede insaciável por conhecimento e, depois da rebelião liderada por Turner em 1831:

\begin{abstract}
A legislação que proibia o acesso da população escrava a educação recrudesceu em todo o Sul. Nas palavras de um dos códigos que normatizavam a escravidão no país, 'ensinar escravos a ler e a escrever tende a incutir a insatisfação em suas mentes e a produzir insurreição e rebelião'. [...] Em todo o Sul, os proprietários de escravos recorriam ao tronco e ao açoite para conter o desejo irreprimível que escravas e escravos tinham de aprender. O povo negro queria ser educado. (DAVIS, 2016, p. 113).
\end{abstract}

Todavia, apesar do veto em relação à educação dos escravizados, muitos foram aqueles que, às margens, tiveram acesso ao universo da cultura letrada nos Estados Unidos. (HAGER, 2013). 
O nascimento de uma nação destaca a força libertadora da palavra escrita e da leitura, sob as lentes de um homem nascido na escravidão. Nat Turner passa a interpretar a Bíblia à sua maneira, e a ver as ambiguidades na leitura que muitos senhores fizeram desse livro sagrado no sentido de legitimar a escravidão. Nat Turner passou a questionar o sistema escravista. Em seus cultos direcionados aos companheiros de escravidão, começou a nutrir sentimentos de liberdade.

Outro caso emblemático de uso da palavra escrita para a conquista da liberdade foi vivenciado por Solomon Northup (2014, p. 17):

Tendo nascido um homem livre, por mais de 30 anos gozado da bênção da
liberdade em um estado livre e sido, ao final desse período, sequestrado e
vendido como escravo, assim permanecendo até ser felizmente resgatado no mês
de janeiro de 1853 , após uma servidão de 12 anos, foi sugerido que um relato de
minha vida e de minhas desventuras não seria desprovido de interesse para o
público.

O fragmento acima é parte de Doze anos de escravidão, originalmente publicado nos Estados Unidos, em 1853, relatando, em primeira pessoa, o período de 12 anos no qual Solomon Northup, homem negro e livre, foi sequestrado e escravizado em fazendas no sul dos Estados Unidos. Solomon sabia ler e escrever, e a partir destas habilidades, redigiu uma carta para se libertar.

Essa autobiografia inspirou o roteiro de 12 anos de escravidão, dirigido por Steve McQueen, vencedor de inúmeros prêmios, dentre os quais, o Oscar de Melhor Filme do Ano, de 2013. Apenas no século XXI a obra mereceu a tradução para a língua portuguesa, muito em função do extraordinário sucesso do filme, mais de 100 anos depois da traumática experiência vivida por Solomon Northup.

Assim como Nat Turner e Solomon Northup, muitos foram os escravizados capazes de ler e escrever nos Estados Unidos - que tiveram suas trajetórias conhecidas e pesquisadas, dentre os quais destaco os escritos, em primeira pessoa, de sujeitos como Booker Washington (1856-1915), Harriet Jacobs (1813-1897), Amanda Smith (18371915), e outros tantos que publicaram autobiografias na forma de livro. (BLASSINGAME, 1977). A partir das escritas de si, dos relatos de missionários, dentre outras fontes, o livro Self-Taught: African American Education in Slavery and Freedom, de Heather Williams, explora os esforços dos próprios sujeitos, escravizados e libertos, na luta pela educação e indica, também, a importância da atuação de grupos diversos, tais como, os missionários religiosos, indicando o poder político a partir do conhecimento da palavra escrita nos Estados Unidos. (WILLIAMS, 2005).

O poder da palavra escrita em tempos de escravidão nos Estados Unidos já foi o horizonte nas análises de muitas pesquisas acadêmicas. Em 1991, Janet Cornelius publicou When I Can Read My Title Clear: Literacy, Slavery, and Religion in the Antebellum South. 
A partir de fontes variadas, tais como narrativas de vida de escravizados, diários e registros de igrejas, a autora traz importante contribuição a respeito de um tema até então negligenciado: o poder da alfabetização no mundo dos escravizados. A autora também examina as controvérsias em torno da legislação que proibia a alfabetização dos escravizados, e identificou certo exagero da extensão da legislação antialfabetização. De acordo com as análises da autora, aproximadamente $10 \%$ de escravizados sabiam ler nos Estados Unidos no início do século XIX.

Seguindo os rastros de Janet Cornelius, a historiadora Edith Jenifer Monaghan avançou nas pesquisas a respeito do poder da palavra escrita no mundo dos escravizados. A autora defende a tese de que a leitura era para os escravizados, enquanto o domínio da escrita era voltado para os livres no período colonial nos Estados Unidos. Segundo a autora, à medida que se examina a relação entre alfabetização e liberdade, diferentes perguntas devem ser feitas em relação às diferentes habilidades. (MONAGHAN, 2000). Ensinar a leitura sem a escrita foi um caminho para aqueles que almejavam formar cristãos, sem abolir a escravidão. A escritura era perigosa, nesse sentido. (MONAGHAN, 2007, p. 241). Dentre as fontes analisadas nos estudos de Jenifer Monaghan, destacam-se os anúncios de jornais e as trajetórias de escravizados, dentre os quais Pompey Fleet, Phillis Wheatley e Frederick Douglass.

A existência de escravizados letrados nos Estados Unidos do século XVIII também foi o foco dos estudos de Antonio Bly, em pesquisa, nos jornais, a partir de anúncios de escravos fugidos. (BLY, 2008). A luta pelo direito à educação da população afrodescendente no pós-abolição, nos Estados Unidos, a partir do pensamento de intelectuais - como Booker Washinton, nascido na escravidão e autor de autobiografias -, foi o foco do artigo Fighting injustice through education, de Cally Waite e Margaret Crocco (2004).

O Brasil também produziu narrativas a respeito do poder da palavra e da educação no mundo dos escravizados. Do filme Quanto Vale ou É por Quilo? - dirigido por Ségio Bianchi, em 2005, baseado em documentação do Tribunal da Relação do Rio de Janeiro/Arquivo Nacional, em finais do século XVIII - destaco a história de Adão, escravo alugado para trabalhar na contabilidade de uma fábrica de erva-mate. Adão sabia escrever e contar muito bem, o que traria muito lucro para seu senhor. Provavelmente, a instrução de Adão era considerada um investimento para o seu dono. Como e onde Adão aprendera a escrever e a contar? Adão também sabia ler?

Uma das possibilidades de instrução para escravizados é o autodidatismo, prática altamente difundida no Brasil do século XIX. O esforço do próprio sujeito no sentido de educar-se não deve ser menosprezado nas análises, pois sim, "[...] o autodidata tinha, muitas vezes, um entendimento desigual e difícil, mas era seu. Como tinha sido obrigado a encontrar seu próprio caminho intelectual, pouco tomou de empréstimo: sua mente não se 
movia dentro da rotina estabelecida de uma educação formal.” (THOMPSON, 1988, p, 48).

É importante salientar que apesar de impedimentos legais em relação à presença de cativos nas escolas em diferentes períodos e regiões, pesquisas desenvolvidas no campo da História da Educação vêm contrariando a premissa de uma exclusão absoluta de escravos no que tange ao acesso à instrução e à educação no período imperial. É preciso considerar o processo educativo de forma ampla, para além dos bancos escolares. $\mathrm{O}$ aprendizado da língua - muitas vezes, pela escuta e pela oralidade -, o aprendizado de instrumentos musicais e de diferentes ofícios - em diferentes espaços e meios -, e o autodidatismo, são algumas das possibilidades de ações importantes na compreensão dos caminhos empreendidos pelos escravizados rumo à inserção no universo da cultura escrita. (SILVA, Alexandra, 2018).

Sujeitos em trânsito, os escravizados se deslocavam em diferentes localidades e culturas. Apesar da hierarquia, havia mobilidade social e espacial. Eles próprios procuravam se instruir, de diferentes maneiras. Aprendiam saberes variados. Para fugir, sobreviver, resistir, lutar. Porque sim, palavras podem libertar.

\section{A LibERDADE É UMA LUTA CONSTANTE: CAMINHOS PARA A EDUCAÇÃO}

A partir dos ensinamentos de Angela Davis (2018, p. 5), para a qual, “[...] a liberdade é uma luta constante", sigo o rastro de alguns filmes que ajudam a pensar as lutas pela liberdade e pela educação no pós-abolição.

No caso brasileiro, destaco Tenda dos Milagres, filme dirigido por Nelson Pereira dos Santos e lançado em 1977, com roteiro adaptado do livro homônimo de Jorge Amado. A trama gira em torno da elaboração de um filme sobre o intelectual Pedro Archanjo, a partir do olhar do jornalista e poeta Fausto Pena, interpretado por Hugo Carvana. A primeira cena introduz o telespectador na metalinguagem, no diálogo entre Fausto Pena e Dadá:

Fausto Pena: Ai, Dadá. O filme pesquisa a vida de Pedro Archanjo, um baiano do passado que a polícia da época classificava como um pardo, paisano e pobre metido a sabichão e a porreta. Mas que na realidade era um dos maiores cientistas sociais do mundo. Do mundo não, do Brasil, né, Dadá? É do Brasil... Mas é claro. Vê só, bota ai. Pedro Archanjo Ojuobá um dos maiores cientistas do mundo.

Dadá: É... mas para mim esse cabra não tem cara de cientista não [...]. Você ainda passa botando uns óculos, mas esse Archanjo não. (TENDA DOS MILAGRES, 1977).

Por que Pedro Archanjo não parecia cientista? Um homem negro e pobre não poderia ser cientista? 
O interesse em investigar a vida do intelectual negro Pedro Archanjo surge a partir da chegada de um importante professor da Universidade de Columbia/Estados Unidos. A partir daí, todos na cidade passam a perguntar: quem foi Pedro Archanjo, até então ignorado e silenciado pelos círculos letrados e de poder.

Pedro Archanjo era um autodidata e bedel da Faculdade de Medicina da Bahia que ousava questionar a formação brasileira e valorizar as culturas afrobrasileira e o candomblé. O personagem foi inspirado no intelectual Manuel Raymundo Querino, nascido na Bahia no ano de 1851, tendo sido professor, político, artista:

Brasileiro afrodescendente, nascido em Santo Amaro da Purificação no recôncavo baiano em 28 de julho de 1851 [...]. Militante das causas dos trabalhadores livres e escravos e de outras questões sócio-políticas que afetaram diretamente os interesses das classes artísticas e operárias [...]. (LEAL, 2009, p. 20).

O filme é importante porque evidencia o caráter violento do racismo no Brasil, em suas mais diferentes camadas. Violências físicas e simbólicas em diferentes aspectos ajudam a desmitificar a ideia de que o Brasil é uma democracia racial. A partir dos personagens Pedro Archanjo e Tadeu é possível discutir a ideia de que a ascensão social e a mestiçagem não atenuam o racismo. Tadeu, negro, engenheiro, é rejeitado pela família de sua noiva exatamente por apresentar um único "defeito": a descendência africana e a cor da pele. Outro aspecto do racismo à brasileira é o não reconhecimento dos aspectos intelectuais da população afrodescendente. Assim como Manuel Querino, o personagem Pedro Archanjo sofreu com a falta de reconhecimento dos ditos cientistas da faculdade de medicina. Manuel Querino vem merecendo alguma atenção no âmbito da produção acadêmica, com destaques para os trabalhos de Sabrina Gledhill (2014), Schueler (2016), dentre outros.

Vem de Manuel Querino uma importante pista para os (as) historiadores (as) da educação. No livro A raça africana, o intelectual baiano defende que a maior parte dos professores do Império no Brasil era da cor negra. Ainda nas primeiras décadas da Republica, tal presença, apesar de ignorada por muitos estudiosos, ainda se fazia presente. Neste sentido, um filme que também pode ser exibido e analisado em sala de aula, para pensar o preconceito racial e os resquícios da sociedade escravista brasileira na passagem do século XIX para o XX, é Vida de Menina, adaptação do livro Minha vida de menina (1942), de Helena Morley, pseudônimo de Alice Brant, a partir de um diário escrito por ela entre seus 13 e 15 anos, na cidade de Diamantina, MG. O filme foi dirigido por Helena Solberg e protagonizado por Ludmila Dayer no ano de 2004. Apesar das poucas falas e da falta de protagonismo de atores negros, o professor de literatura de Helena é afrodescendente, e desafia a menina a escrever. 
A respeito dos professores negros, destaco alguns interessantes e importantes trabalhos que vem sendo produzidos. Adriana Silva teceu importante análise a partir da experiência do professor negro Pretextato e da escola exclusiva para negros e pardos na Corte Imperial. (SILVA, Adriana, 2000). A trajetória do professor Hemetério dos Santos foi o centro da análise na dissertação de mestrado defendida por Laura Silva (2015), e capítulo de livro de Schueler e Rizzini (2017), apenas para citar alguns trabalhos.

Outro filme importante e que ajuda a discutir racismo e educação no Brasil é o premiado documentário Menino 23- Infâncias Perdidas no Brasil, dirigido por Belisario Franca e lançado no ano de 2016. O documentário parte da tese de doutorado Educação, autoritarismo e eugenia: exploração do trabalho e violência à infância desamparada no Brasil, do historiador Sydney Aguiar. A produção aborda a escravização de meninos negros por um fazendeiro branco simpatizante do nazismo, em pleno Brasil republicano, e evidencia a perversidade do racismo. O pós-abolição no Brasil é um período de incentivo à eugenia e ao embranquecimento da população, sendo a escola brasileira o lugar para a construção dos "diplomas de brancura", num projeto nacional que visava "[...] transformar uma população geralmente não-branca e pobre em pessoas embranquecidas na sua cultura, higiene, comportamento, e até, eventualmente, na cor da sua pele." (DÁVILA, 2006, p. 13).

Diferente dos Estados Unidos, o Brasil não criou escolas e universidades para a população afrodescendente; também não tivemos por aqui, leis de segregação. $O$ que não significa que não tenha havia racismo. O Brasil optou pela valorização da branquitude e pela negação da negritude como um projeto para a nação. (ARAUJO, 2000).

Para compreender como as especificidades das lutas por educação e contra o preconceito racial nos Estados Unidos, destaco o excelente documentário Tell them we are rising: the story of black Colleges and Universities (Avisem que estamos chegando: a história dos colégios e universidades negras), lançado em 2017, com a direção de Stanley Nelson. A partir de rico acervo, com imagens de arquivo, voz in/off e da fala de diferentes pesquisadores do tema, o filme explora a luta da população afroamericana por educação desde os tempos da escravidão. Através do roteiro, é possível compreender que não havia entendimento único em relação à educação dos afroamericanos, com destaque para os debates travados entre Booker T. Washington e W. E. B. Dubois. Para Washington, nascido escravo, a educação da população negra deveria qualificá-la para o trabalho. Na perspectiva de W. E. B Dubois, Washington estaria contribuindo para a ideia de que os negros são inferiores intelectualmente, e que apenas deveriam servir às pessoas brancas. Dubois defendia que o negro deveria promover a própria educação, para emancipar-se. O documentário fundamenta-se na fala de pesquisadores com trabalhos de referência no tema (GASMAN, 2005; SANDERS, 2016; ALLEN, 2009; WILLIAMS, 2005). 
MULHERES NEGRAS NO CINEMA: EDUCAÇÃO, RESISTÊNCIA E IGUALDADE

Outra temática importante no ensino de História da Educação é o protagonismo das mulheres negras e a relação delas com a educação e com a palavra escrita. Neste sentido, elejo dois filmes para análise.

O livro A cor púrpura (The Color Purple), de Alice Walker, publicado originalmente em 1982, inspirou o roteiro - escrito pela própria autora - do filme homônimo, lançado em 1985 e dirigido por Steven Spielberg. Protagonizado por Whoopi Goldberg, além de Danny Glover e Oprah Winfrey. Com fortes traços autobiográficos, o drama se passa no início do século XX, no estado da Geórgia, Estados Unidos. Começa com Celi ainda menina, por volta dos 13 anos, negra, sem instrução formal, violentada pelo padrasto, mãe de dois filhos, entregue para ser esposa de Sinhô, interpretado por Danny Glover. Nettie, a irmã mais nova, filha biológica do padrasto, pôde frequentar a escola, e partilha com Celie os caminhos da leitura e da escrita.

Para escapar dos assédios de Sinhô, Nettie foge, e acompanha uma família de missionários à África. Com o pouco que aprendeu sobre a palavra escrita, Celie se esforça para escrever cartas para a irmã distante, e assim os anos passam. As palavras, seja pela escrita de cartas, seja pela leitura, preenchem a solidão de Celie, que escreve para a irmã e para Deus, sem resposta.

De qualquer maneira, por meio das cartas, Celie mantinha seus vínculos e ligações afetivas, pois, conforme salienta Antonio Castillo Gómez, as epístolas estabelecem união entre quem as escreve e o destinatário, seja individual ou coletivo, preservando os vínculos na distância e se configurando como um espaço através do qual se expressam e se desenvolvem as identidades pessoais, familiares ou sociais. (CASTILLO GÓMEZ, 2002, p. 101).

O autor espanhol acentua ainda que a distância é fundamental ao se falar do epistolário como uma produção discursiva, complementar à presença e à aparência da realidade, numa conversação entre ausentes. Desse modo, “[...] as cartas, explicitam um duplo ato de representação: por um lado, o da pessoa ausente que se mostra através do signo escrito e do suplemento que carrega, e por outro, por sua função como espaço de conhecimento pessoal.” (CASTILLO GÓMEZ, 2002, p. 104, tradução nossa).

Recorrendo às noções básicas dos manuais de escrita de cartas, deve-se atentar para, ao menos, seis aspectos que perpassam a comunicação através de uma missiva: quem escreve, a quem, por que, o que se escreve, quando e de que maneira se fala. (CASTILLO GÓMEZ, 2002, p. 104).

Além do vínculo imaginário mantido com a irmã através das cartas, Celie estabelece relações de amizade com outras mulheres negras, dentre as quais, Sofia e Shug 
Avery, amante do Sinhô. Conforme indica Anne Vincent-Buffault, a amizade “[...] estabelece redes de influência, inventa lugares de convivência e laços de resistência enquanto se multiplicam para a maioria as oportunidades de encontros e interações." (VINCENT-BUFFAULT, 1996, p. 9).

A leitura e a escrita ajudam Celie a suportar os abusos do marido. Por fim, ela se revolta e se emancipa. Sem dúvida, o apoio de outras mulheres negras, dentre as quais, a irmã Nettie, que a alfabetiza, foram cruciais neste processo de libertação de Celie.

Outra película ficcional que aborda a força da palavra escrita na experiência de mulheres negras é Histórias Cruzadas. Dirigido por Tate Taylor e lançado em 2011, o filme protagonizado por Viola Davis rendeu um Oscar de atriz coadjuvante para Octavia Spencer. O drama ambienta-se em 1963, no Mississippi, Estados Unidos, abordando o racismo e a opressão entre empregadas domésticas negras e suas senhoras brancas. $\mathrm{O}$ conflito se acentua com a chegada da jovem Eugenia Skeeter, que decide colocar o dedo na ferida - redigindo um livro - ao ouvir os depoimentos das empregadas. A partir do seu escrito, e da percepção da conexão em torno da opressão sofrida pelas mulheres negras, Aibileen Clark (Viola Davis), rompe a relação com a patroa e vai embora, decidida a tornar-se escritora da própria história.

Angela Davis fundamenta a análise que evidencia como a emancipação da mulher branca se deu graças ao trabalho doméstico realizado pelas mulheres negras:

\footnotetext{
Devido à intrusão adicional do racismo, um vasto número de mulheres negras teve de cumprir as tarefas de sua própria casa e também os afazeres domésticos de outras mulheres. E com frequência as exigências do emprego na casa de uma mulher branca forçavam a trabalhadora doméstica a negligenciar sua própria casa e até mesmo suas próprias crianças. Enquanto empregadas remuneradas, elas eram convocadas a ser mães e esposas substitutas em milhões de casas de famílias brancas. (DAVIS, 2016, p. 239).
}

A cor púrpura e Histórias Cruzadas estão conectados pela representação da mulher negra como protagonista, que rompe as opressões a partir da força da palavra escrita. Essa trajetória, de uma mulher negra que se instrui, é diferente daquelas usualmente construídas da mulher negra como objeto, sem mente, apenas corpos. Nas palavras de Bell Hooks, mesmo "[...] quando eruditos negros escrevem sobre a vida intelectual negra em geral, só focalizam as vidas e obras de homens." (HOOKS, 1995, p. 466). Tais problemas levam as seguintes indagações: Por que uma mulher negra não podia ser livre para pensar? Por que não se dá visibilidade às diferentes trajetórias de mulheres que, apesar das relações opressivas, se instruíram e se tornaram autoras das próprias histórias?

Hidden Figures, cuja tradução literal é figuras ocultas, é um filme que chegou às telas brasileiras como Estrelas além do tempo. Contudo, o título original em inglês sintetiza mais o que proponho discutir neste artigo: o processo de invisibilização e de falta de reconhecimento das mulheres negras na ciência. O filme, lançado no ano de 2016, é 
estrelado pelas atrizes Taraji P. Henson, Octavia Spence e Janelle Moná, e se inspira na história real de três matemáticas da NASA.

A primeira cena de Estrelas além do tempo se passa no estado da Virgínia, no ano de 1926, quando a menina Katherine Johnson, de apenas 8 anos, já resolvia um problema matemático considerado complexo, numa escola de crianças negras de faixa etária mais elevada. Adulta e graduada em Matemática, compartilha com as amigas Dorothy Vaughn e Mary Jackson as dores do racismo e da falta de reconhecimento de sua habilidade e formação. Em função da lei de segregação racial, ainda vigente na década de 1960, as mulheres negras eram obrigadas a ocupar funções de menos prestígio na NASA, por mais qualificadas e competentes que fossem. Em outra cena do filme, Katherine Johnson resolve um problema matemático que nenhum homem branco da NASA conseguia resolver. A partir daí, ela passa a contribuir na execução de um projeto importante na corrida espacial almejada pelos Estados Unidos.

O filme também mostra como a personagem Mary Jackon se tornou a primeira engenheira negra da NASA. Ela precisou recorrer à justiça para obter a autorização que a permitia cursar engenharia junto a pessoas brancas.

Altamente qualificadas e educadas, as três mulheres negras representadas no filme lutaram para superar o racismo e ascender na hierarquia da NASA. Elas precisavam provar, a todo tempo, que eram capazes, negando a ideologia dominante para a qual:

[...] a população negra era supostamente incapaz de progressos intelectuais. Afinal, essas pessoas haviam sido propriedade, naturalmente inferiores quando comparadas ao epítome branco da humanidade. Mas, se fossem realmente inferiores em termos biológicos, as pessoas negras nunca teriam manifestado desejo nem capacidade de adquirir conhecimento. Portanto, não teria sido necessário proibi-las de aprender. $\mathrm{Na}$ realidade, é claro, a população negra sempre demonstrou uma impaciência feroz no que diz respeito a aquisição de educação. (DAVIS, 2016, p. 109).

As cientistas representadas no filme precisam provar que não eram "corpos sem mente". Tais problemas levam as seguintes indagações: por que tanto silêncio em torno da dimensão intelectual da mulher negra?

Acompanhando Bell Hooks, os corpos negros femininos "[...] são postos numa categoria em termos culturais tida como bastante distante da vida mental." (HOOKS, 1995, p. 469). A autora sinaliza ainda que dentro das hierarquias de sexo/raça/classe, as mulheres negras "[...] sempre estiveram no nível mais baixo. O status inferior nessa cultura é reservado aos julgados incapazes de mobilidade social por serem vistos em termos sexistas, racistas e classistas como deficientes incompetentes e inferiores." (HOOKS, 1995, p. 469).

Nas palavras de Bell Hooks: 
Do outro lado das representações das negras como selvagens sexuais desqualificadas e/ou prostitutas há o estereotipo da mãe preta. Mais uma vez essa imagem registra a presença feminina negra como significada pelo corpo neste caso a construção de mulher como mãe de peito amamentando e sustentando a vida de outros. Significativamente a proverbial mãe preta cuida de todas as necessidades dos demais em particular dos mais poderosos. (HOOKS, 1995, p. 469).

Os filmes protagonizados por mulheres negras, aqui analisados, ajudam a compreender a ideia de que a luta pelo empoderamento das mulheres afro-americanas não é recente. Conforme Angela Davis salienta:

\footnotetext{
Por quase um século, temos nos organizado em grupos voltados a desenvolver coletivamente estratégias que iluminem o caminho rumo ao poder econômico e político para nós mesmas e para nossa comunidade. Ao longo da última década do século XIX, após serem repetidamente rechaçadas pelo racialmente homogêneo movimento pelos direitos das mulheres, as mulheres negras formaram seu próprio movimento associativo. (DAVIS, 2017, p. 15).
}

Filmes como A cor púrpura, Histórias Cruzadas e Estrelas além do tempo são importantes ferramentas pedagógicas no ensino de História da Educação, porque conferem visibilidade ao protagonismo das mulheres negras e a importância da educação na experiência de tais mulheres. Os filmes ensinam a transgredir e mostram que a educação deve ser uma prática para a liberdade.

No Brasil, produções como Café com canela e o Dia de Jerusa ajudam a pensar a importância do movimento no qual "[...] devemos sempre tentar erguer-nos enquanto subimos” (DAVIS, 2017, p. 22), pois quando as mulheres negras se movimentam, “[...] erguemos conosco nossos irmãos de minorias étnicas, nossas irmãs da classe trabalhadora branca e, efetivamente, todas as mulheres que sofrem os efeitos da opressão sexista." (DAVIS, 2017, p. 23).

O longa metragem ficcional Café com canela é o filme de estreia de Ary Rosa e Glenda Nicácio na direção, no ano de 2017. O roteiro mostra como a relação entre uma professora e uma ex-aluna foi o caminho rumo à cura para a dor da perda de um filho. A relação de escuta também é marcante no curta Dia de Jerusa, dirigido por Viviane Ferreira e lançado no ano de 2014. Uma simples pesquisa de opinião se torna o caminho para a emersão de sentimentos e memórias sufocados. Duas mulheres negras, afastadas por gerações, conectadas para muito além das palavras de um questionário. Silvia é uma jovem que ganha a vida realizando pesquisa de opinião sobre um sabão em pó. Jerusa é uma solitária mulher negra de 77 anos. Um filme que faz emergir memória, afeto, resistência e palavras que ajudam a romper a solidão e o silêncio. No final, o encontro mudou as duas. Silvia descobre, durante aquela conversa, que passou no vestibular. Travessia que segue.

\section{ÚLTIMA CENA: À GUISA DE CONCLUSÃO}


Estruturei este texto em torno de filmes que abordam a luta pela emancipação de pessoas afrodescendentes no Brasil e nos Estados Unidos, a partir das relações dos diferentes protagonistas com livros, leitura e escrita e com a educação, de maneira ampla. Tal cinematografia pode ser exibida e discutida no âmbito da disciplina História da Educação, pois permite o aprofundamento em torno de temáticas diversas. Mas, afinal, a educação é um ato de resistência? Educar-se pode ser um caminho para a conquista da liberdade?

Todos os filmes analisados indicam, de alguma maneira, que a educação é um meio para transformar a realidade dos sujeitos em situação de opressão. A educação pode ameaçar os projetos daqueles que tentam construir realidades e relações baseadas em intolerâncias, autoritarismos e violências. $\mathrm{O}$ acesso à palavra escrita foi signo de luta $\mathrm{e}$ resistência para centenas de mulheres e homens em diferentes momentos. $\mathrm{O}$ cinema pode servir como ferramenta aliada nessa luta, e fonte de conhecimento. Este trabalho procurou também dar visibilidade ao protagonismo dos diferentes sujeitos, na luta pelo direito de terem sua identidade reconhecida e por representatividade. Raízes de ébano, porque com resistência, os personagens representados nos filmes, aqui analisados, foram protagonistas de histórias de resistência, no plural.

\section{REFERÊNCIAS}

12 ANOS de escravidão. Direção: Steve McQueen. Estados Unidos; Reino Unido: Plan B, 2013. 1 DVD, (134 min).

A COR púrpura. Direção: Steven Spielberg. Estados Unidos: Amblin Entertainment; The Warner Bros, 1985. 1 DVD, (154 min).

ALLEN, W. R.; GRIFFIN, E. K. Towards a brighter tomorrow: collge barriers, hopes and plans of black, latino/a and asian american students in California. Charlotte, NC: Information Age Publishing, 2009.

ARAUJO, J. Z. A negação do Brasil. São Paulo: SENAC, 2000.

AVISEM que estamos chegando. Direção: Stanley Nelson. Estados Unidos: Firelight Films, 2017. 1 DVD, (85 min).

BARROS, S. A. P. Negrinhos que por ahi andão: escolarização da população negra em São Paulo (1870-1920). 2005. Dissertação (Mestrado em Educação) - Faculdade de Educação, Universidade de São Paulo, São Paulo, 2005.

BARROS, S. Universo letrado, educação e população negra na Parahyba do Norte (Século XIX). São Paulo: Ed. da USP, 2017. 
BLASSINGAME, J. Slave testimony: two centuries of letters, speeches, interviews and autobiographies. Louisiana State: Univ. Press, 1977.

BLY, A. Pretends he can read: Runaways and literacy in Colonial America, 1730-1776. Early American Studies, 2008.

CAFÉ com canela. Direção: Ary Rosa e Glenda Nicacio. Brasil, 2017. 1 DVD, (102 min). ${ }^{2}$

CASTILLO GÓMEZ, A. "Del tratado a la práctica. La escritura epistolar en los siglos XVI y XVII”. In: SAÉZ, C.; CASTILLO GÓMEZ, A. (Ed.). La correspondencia en la historia: modelos y prácticas de la escritura epistolar. Madrid: Calambur, 2002. p. 79-108

CONKLIN, G. The science fiction galaxy. New York: Permabooks, 1950.

CORNELIUS, J. When i can read my title clear: literacy, slavery, and religion in the antebellum south. Columbia: University of South Carolina Press, 1991.

DÁVILA, J. Diploma de brancura: política social e racial no Brasil 1917-1945. São Paulo: Ed. da UNESP, 2006.

DAVIS, A. A liberdade é uma luta constante. São Paulo: Boitempo, 2018.

DAVIS, A. Mulheres, cultura e política. São Paulo: Boitempo, 2017.

DAVIS, A. Mulheres, raça e classe. São Paulo: Boitempo, 2016.

FELIPE, D. A. Narrativas para alteridade: o cinema na formação de professores e professoras para o ensino de história e cultura afrobrasileira e africana na educação básica. 2009. Dissertação (Mestrado em Educação) - Universidade Estadual de Maringá, Paraná, 2009.

FERRO, M. Cinema e história. Rio de Janeiro: Paz e Terra, 1992.

FIGUEIREDO, C. Admirável comunicação nova: um estudo sobre a comunicação nas distopias literárias. 2011. Tese (Doutorado em Comunicação) - Universidade Federal de Pernambuco, Recife, 2011.

FONSECA, M. V. Pretos, pardos, crioulos e cabras nas escolas mineiras do século XIX. 2007. Tese (Doutorado em Educação) - Universidade de São Paulo, São Paulo, 2007.

GASMAN, M. The role of faculty in fundraising at black colleges: what is it and what can it become? International Journal of Educational Advancement, n. 5, v. 2, p. 171-179, 2005 .

GINZBURG, C. O fio e os rastros. Verdadeiro, falso, fictício. Tradução de Rosa Freire d'Aguiar e Eduardo Brandão. São Paulo: Companhia das Letras, 2007. 
Artigo

doi: $10.20396 /$ rho.v18i3.8652200

GINZBURG, C. O queijo e os vermes. O cotidiano e as idéias de um moleiro perseguido pela Inquisição. São Paulo: Cia das Letras, 1987.

GLEDHILL, S. Travessias racialistas no Atlântico negro: reflexões sobre Booker T. Washington e Manuel R. Querino. 2014. Tese (Doutorado em Estudos Étnicos e Africanos) - Universidade Federal da Bahia, Salvador, 2014.

HAGER, C. Word by word: emancipation and the act of writing. Cambridge, MA: Harvard University Press, 2013.

HISTÓRIAS cruzadas. Direção: Tate Taylor. Estados Unidos: Walt Disney Studios, 2011. 1 DVD, (137 min).

HOOKS, B. Ensinando a transgredir: a educação como prática da liberdade. São Paulo: Martins Fontes, 2017.

HOOKS, B. Intelectuais negras. Revista Estudos Feministas, Florianópolis, v. 3, n. 2, p. 464-478, 1995.

JESUS, R. E. Diversidade étnico-racial no Brasil: os desafios à Lei no 10.639, de 2003. Revista retratos da Escola, Brasília, v. 7, n. 13, p. 399-412, jul./dez. 2013. Disponível em: <http://retratosdaescola.emnuvens.com.br/rde/article/viewFile/314/484>. Acesso em: 18 dez. 2017.

LEAL, M. G. Manuel Querino: entre letras e lutas na Bahia. São Paulo: Annablume, 2009.

MAC CORD, M.; ARAÚJO, C.; GOMES, F. Rascunhos cativos: educação, escolas e ensino no Brasil escravista. Rio de Janeiro: 7 Letras, 2017.

MENINO 23: infâncias perdidas no Brasil. Direção: Belisario Franca. Brasil: Globo Filmes, 2016. 1 DVD, (80 min).

MONAGHAN, E. Learning to read and write in Colonial America. Massachusetts: University of Massachusetts Press, 2007.

MONAGHAN, E. Reading for the enslaved, writing for the free: refletions on liberty and literacy. Worcester: American Antiquarian Society, 2000.

NORTHUP, S. Doze anos de escravidão: a história real de Solomom Northup. São Paulo: Companhia das Letras, 2014.

O DIA de Jerusa. Direção: Viviane Ferreira. Brasil: Odun, 2014. (20 min). Disponível em: <https://www.youtube.com/watch?v=7y9aNEoS7YA>. Acesso em: 11 set. 2018. 
O NASCIMENTO de uma nação. Direção: D. W. Griffith. Roteiro: D. W. Griffith e Frank E. Woods. Estados Unidos: Century, 1915. (193 min). Disponível em: <https://www.youtube.com/watch?v=I3kmVgQHIEY>. Acesso em: 11 set. 2018.

O NASCIMENTO de uma nação. Direção: Nate Parker. Estados Unidos: Bron Studios, 2016. 1 DVD, (120 min).

QUANTO vale ou é por quilo? Direção: Sergio Bianchi. Brasil, 2005. 1 DVD, (104 min).

RIBEIRO, B.; CARVALHO, C. H.; SOUZA, S. (Org.). Cinema e ensino de história da educação. Campinas: Alínea, 2013.

SANDERS, C. A. Chance for change: head start and mississippi's black freedom struggle. United States: University of North Carolina Press, 2016.

SARLO, B. A história contra o esquecimento. In: . Paisagens imaginárias. São Paulo: Ed. da EDUSP, 1997.

SCHUELER, A.; RIZZINI, I. Hemetério José dos Santos: professor e intelectual negro nas disputas pela educação na cidade do Rio de Janeiro. In: MAC CORD, M.; GOMES, F. (Org.). Rascunhos cativos. Educação, escolas e ensino no Brasil escravista. 1. ed. Rio de Janeiro: 7 Letras, 2017. p. 77-99.

SCHUELER, A. Trajetórias cruzadas e ação docente em luta por educação: André Rebouças, José do Patrocínio e Manuel Querino. In: FONSECA, M. V.; BARROS, S. (Org.). A história da educação dos negros no Brasil. 1. ed. Niterói, RJ: Ed. da EDUFF, 2016. p. 191-216.

SHARPE, J. "A história vista de baixo". In: BURKE, P. (Org.). A escrita da história: novas perspectivas. São Paulo: Ed. da UNESP, 1992.

SILVA, A. L. O saber que se anuncia: o poder da palavra em tempos de escravidão. Revista Brasileira de História da Educação, v. 18, p. 1-29, 2018.

SILVA, A. M. P. Aprender com perfeição: escolarização e construção da liberdade na Corte na primeira metade do século XIX. Brasília: Plano, 2000.

SILVA, L. dos. S. 'Etymologias preto': Hemetério José dos Santos e as questões raciais de seu tempo (1888-1920). 2015. 150 f. Dissertação (Mestrado em Relações Etnicorraciais) - Centro Federal de educação Tecnológica Celso Suckow da Fonseca, Rio de Janeiro, 2015 .

STYRON, W. As confissões de Nat Turner (biografia). São Paulo: Expressão e Cultura, 1968.

TENDA dos milagres. Direção: Nelson Pereira dos Santos. Rio de Janeiro: Regina Filmes; Embrafilme, 1977. 1 DVD (132 min). 
Artigo

doi: $10.20396 /$ rho.v18i3.8652200

THOMPSON, E. P. A formação da classe operária inglesa III. A força dos trabalhadores. Rio de Janeiro: Paz e Terra, 1988.

THOMPSON, E. P. O termo ausente: experiência. In: A miséria da teoria ou um planetário de erros: uma crítica ao pensamento Althusser. Rio de Janeiro: Zahar, 1981.

VEIGA, C. G. Escola pública para os negros e os pobres no Brasil: uma invenção imperial. Revista Brasileira de Educação, v. 13, n. 39, p. 502-516, 2008.

VIDA de menina. Direção: Helena Solberg. Brasil: Radioarte, 2004. 1 DVD, (101 min).

VINCENT-BUFFAUT, A. Da amizade: uma história do exercício da amizade nos séculos XVIII e XIX. Rio de Janeiro: Jorge Zahar, 1996.

WAITE, C.; CROCCO, M. Fighting injustice through education. History of Education, v. 33, n. 5, p. 573-583, Sep. 2004.

WILLIAMS, H. Self-Taught: african american education in slavery and freedom. Chapel Hill: University of North Carolina Press, 2005.

Notas

${ }^{1}$ Doutora em Educação pela Universidade do Estado do Rio de Janeiro (Uerj), com período de bolsa sanduíche financiado pela Capes na Universidad de Alcalá e bolsa Doutorado nota 10 da Faperj. Bacharel, licenciada e mestre em História Social pela Universidade Federal Fluminense (UFF). Atuou como professora adjunta do Departamento de História da UFMT (2013-2015) e professora permanente do PPGHIS/UFMT (2014-2016). Atualmente é professora adjunta da Faculdade de Educação da Uerj, Campus Maracanã, e professora no ProPed/Uerj. E-mail: alexandralima1075@gmail.com

${ }^{2}$ A este respeito, destaco importantes referências: Silva, 2000; Barros, 2005; Fonseca, 2007; Veiga, 2008, Barros, 2017; Mac Cord, M.; Araújo, C.; Gomes, 2017.

Submetido em: 10/04/2018

Aprovado em: 20/08/2018

Publicado em: 28/09/2018 